SHORT REPORT

\title{
Identification of the gene for Nance-Horan syndrome (NHS)
}

\author{
S P Brooks, N D Ebenezer, S Poopalasundaram, O J Lehmann, A T Moore, A J Hardcastle
}

J Med Genet 2004;41:768-771. doi: 10.1136/jmg.2004.022517

See end of article for authors' affiliations

......

Correspondence to: Alison J Hardcastle, Division of Molecular Genetics, Institute of Ophthalmology, 11-43 Bath Street, London, ECIV 9EL, UK; a.hardcastle@ ucl.ac.uk

Revised version received 4 June 2004

Accepted for publication

6 June 2004

\begin{abstract}
Background: The disease intervals for Nance-Horan syndrome (NHS [MIM 302350]) and X linked congenital cataract (CXN) overlap on Xp22.

Objective: To identify the gene or genes responsible for these diseases.

Methods: Families with NHS were ascertained. The refined locus for CXN was used to focus the search for candidate genes, which were screened by polymerase chain reaction and direct sequencing of potential exons and intron-exon splice sites. Genomic structures and homologies were determined using bioinformatics. Expression studies were undertaken using specific exonic primers to amplify human fetal cDNA and mouse RNA.

Results: A novel gene NHS, with no known function, was identified as causative for NHS. Protein truncating mutations were detected in all three NHS pedigrees, but no mutation was identified in a CXN family, raising the possibility that NHS and CXN may not be allelic. The NHS gene forms a new gene family with a closely related novel gene NHS-Like1 (NHSL1). NHS and NHSL1 lie in paralogous duplicated chromosomal intervals on Xp22 and 6q24, and NHSL1 is more broadly expressed than NHS in human fetal tissues.

Conclusions: This study reports the independent identification of the gene causative for Nance-Horan syndrome and extends the number of mutations identified.
\end{abstract}

$\mathrm{N}$ ance-Horan syndrome (NHS) is a rare $\mathrm{X}$ linked disease characterised by severe congenital dense nuclear cataracts in hemizygous males. Distinctive dental anomalies are seen in affected males, including supernumerary incisors and crown shaped permanent teeth. Characteristic facial features are anteverted pinnae, long face, and prominent nasal bridge and nose. In addition, approximately $30 \%$ of cases have developmental delay. Carrier females display milder variable symptoms of disease with lens opacities often involving the posterior $\mathrm{Y}$ sutures, and on occasion dental anomalies and the characteristic facial features described. ${ }^{1-5}$

We have investigated a pedigree with $\mathrm{X}$ linked congenital cataract $(\mathrm{CXN})$, associated with ventriculoseptal defect (VSD) in some affected males. ${ }^{6}$ Our genetic mapping of this pedigree suggests that the locus may be synonymous with NHS, and was recently refined to a $3.2 \mathrm{Mb}$ interval. ${ }^{7}$ Affected males with CXN have a total nuclear opacity of the lens, requiring cataract surgery within the first few months of life. Carrier females show a sea-fan type of nuclear lens opacity. Four of the six affected males within this family were found to have VSD, but no cardiac abnormalities have been reported in patients with NHS.

We also studied pedigrees with NHS, independently identifying the NHS gene first reported by Burdon and colleagues, ${ }^{8}$ and found truncating mutations in three pedigrees. After excluding four candidate genes (PPEF1, $R A I 2$, RBBP7, and TL1), ${ }^{7}$ we identified further candidate genes in the region of overlap between the refined NHS and $\mathrm{CXN}$ loci. ${ }^{79}$ A novel gene was identified telomeric to SCML1 and centromeric to microsatellite marker DXS1195 (AFM207ZD6). Numerous expressed sequence tag (EST) hits (NCBI Unigene cluster Hs.444940)_expressed in multiple tissues including fetal eye, brain, kidney, and heartsupported this gene prediction.

\section{METHODS}

Our three NHS families, ascertained after appropriate informed consent and institutional ethical committee board approval were obtained, displayed typical features of the syndrome. The youngest brother of family 1 also had bilateral cleft palate which was repaired in infancy, and the affected male in family three had severe neurological problems (table 1). Direct sequencing of polymerase chain reaction (PCR) amplicons from all predicted coding exons and splice sites was carried out (primers and conditions available on request) on samples from an affected male from the CXN family and NHS families 1, 2, and 3 (fig 1).

\section{RESULTS AND DISCUSSION}

We identified a two base pair (bp) deletion (37383739delTG), causing a frameshift and resulting in a premature stop codon after the addition of 15 novel amino acids (C1246-A1247fsX15), within exon 6 of NHS family 1. A 1 bp deletion (2687delA) was also identified within exon 6 of NHS family 3 (fig 1). Deletion of this one base causes a frameshift which is predicted to result in a premature stop codon following the addition of 10 novel amino acids (Q896fsX10). Our work corroborated the findings of Burdon and colleagues, ${ }^{8}$ which revealed a novel exon 1. Subsequently, oligonucleotide primers were designed to PCR amplify and sequence exon 1 of the NHS gene within NHS family 2 and the CXN family (primers and conditions available on request). A 1 bp deletion was identified within exon 1 (400delC) of NHS family 2, which is predicted to cause a frameshift leading to the addition of 61 novel amino acids before a premature stop codon (R134fsX61). However, no mutation was identified in the CXN family.

All three mutations have been shown to segregate with disease and have not been detected in 200 control chromosomes screened either by direct sequencing of PCR products or by the WAVE nucleic acid fragment analysis system (Transgenomic, Omaha, Nebraska, USA; following manufacturer's instructions).

Abbreviations: CXN, X linked congenital cataract; NHS, Nance-Horan syndrome 
Table 1 Summary of mutations in the NHS gene

\begin{tabular}{|c|c|c|c|}
\hline Sequence change & Exon/intron & Predicted protein & Family and phenotype \\
\hline 3738-3739delTG & Exon 6 & $\mathrm{C} 1246-\mathrm{A} 1247 \mathrm{fs} \times 15$ & $\begin{array}{l}\text { Family } 1 \text { with typical NHS features and bilateral } \\
\text { cleft palate }\end{array}$ \\
\hline 400 delC $^{*}$ & Exon 1 & $\mathrm{R} 134 \mathrm{fs} \times 61$ & Family 2 with typical NHS features \\
\hline 2687 delA & Exon 6 & Q896fsX10 & $\begin{array}{l}\text { Family } 3 \text { with typical NHS features and severe } \\
\text { mental retardation, epilepsy and hypotonia }\end{array}$ \\
\hline 3459delC $†$ & Exon 6 & L1 154fsX28 & \\
\hline 718insG†‡ & Exon 3 & $\mathrm{E} 240 \mathrm{fs} \times 36$ & \\
\hline IVS2-3C $\rightarrow$ G†‡ & Intron 2 & & \\
\hline 2387 ins $C \dagger$ & Exon 6 & $\mathrm{~S} 797 \mathrm{fs} \times 35$ & \\
\hline $1117 \mathrm{C} \rightarrow \mathrm{T} \dagger$ & Exon 5 & R378STOP & \\
\hline
\end{tabular}

${ }^{*}$ Also reported by Burdon and colleagues. tReported by Burdon and colleagues. fldentified within the same family.

An identical 1 bp deletion (400delC) in exon 1 in family 2 reported here was also seen in family 5 described by Burdon and colleagues. ${ }^{8}$ This, however, does not reflect a mutation hotspot as subsequently these families were found to be the same (personal communication). These findings increase the total number of mutations reported in NHS to 7 (table 1), all of which are truncating mutations predicted to result in an aberrant protein product. Four of these lie within exon 6 (three deletions and one insertion), which is considerably larger than the remaining seven coding exons. As exons 1, 2 , and 3 encode isoform A only (the larger isoform of NHS), mutations identified within these exons are predicted to affect expression of isoform A and not isoform B. Two families harbour such mutations (table 1); however, phenotypic differences exist between the families, so there appears to be no direct phenotype-genotype correlation with ablation of isoform A. The possibility that NHS and CXN are allelic has not been excluded by the inability to identify a mutation in the CXN pedigree. Similarly, Burdon and colleagues ${ }^{8}$ observed that another NHS family lacks a mutation in NHS. Further characterisation of the NHS gene may reveal mutations in cryptic exons or regulatory sequences. Interestingly, a mouse model for $\mathrm{X}$ linked congenital cataract maps to the syntenic region of $\mathrm{CXN}$ and $\mathrm{NHS}^{10}$; therefore identification of the causative gene in this model will be important in determining whether CXN and NHS are allelic.
As NHS is a congenital syndrome we evaluated the developmental expression of NHS through PCR analysis of human fetal tissue cDNA (BD Biosciences, Palo Alto, California, USA) and murine tooth cDNA at postnatal day zero, P0, and postnatal day two, P2 (Amersham RNA extraction kit). Primers were designed to amplify a $590 \mathrm{bp}$ and an 268 bp product in genomic DNA and CDNA, respectively, from exons 6 and 7 of human NHS (FW [5'TGCCTGGTACTATCAGCTATG-3'], Rev [5'-TCCTCAGTTGTT CGAGGTTTG- $\left.3^{\prime}\right)$. Primers were also designed to amplify a 206 bp fragment in exon 6 of murine Nhs (Fw[5'ACTGCAACCTCAGCTAGCAG-3'], Rev[5'-TGCTGTACAGTG CCATCTGG-3']). NHS transcripts were detected in murine tooth cDNA at P0 but not at P2 (data not shown). NHS expression was also detected in human fetal brain, thymus, lung and kidney (fig 2C), confirming our initial expression studies in which a $207 \mathrm{bp}$ fragment within exon 6 of human NHS was amplified and detected in the same samples (data not shown). These results are in accord with the expression studies in mouse, showing that the Nhs gene is broadly expressed throughout brain development, and in situ hybridisation studies with Nhs expression found in a range of mouse embryonic tissues-including the lens, brain, craniofacial mesenchyme, and dental primordial. ${ }^{8}$ The significance of the additional expression in human fetal kidney, lung, and thymus is presently not clear.
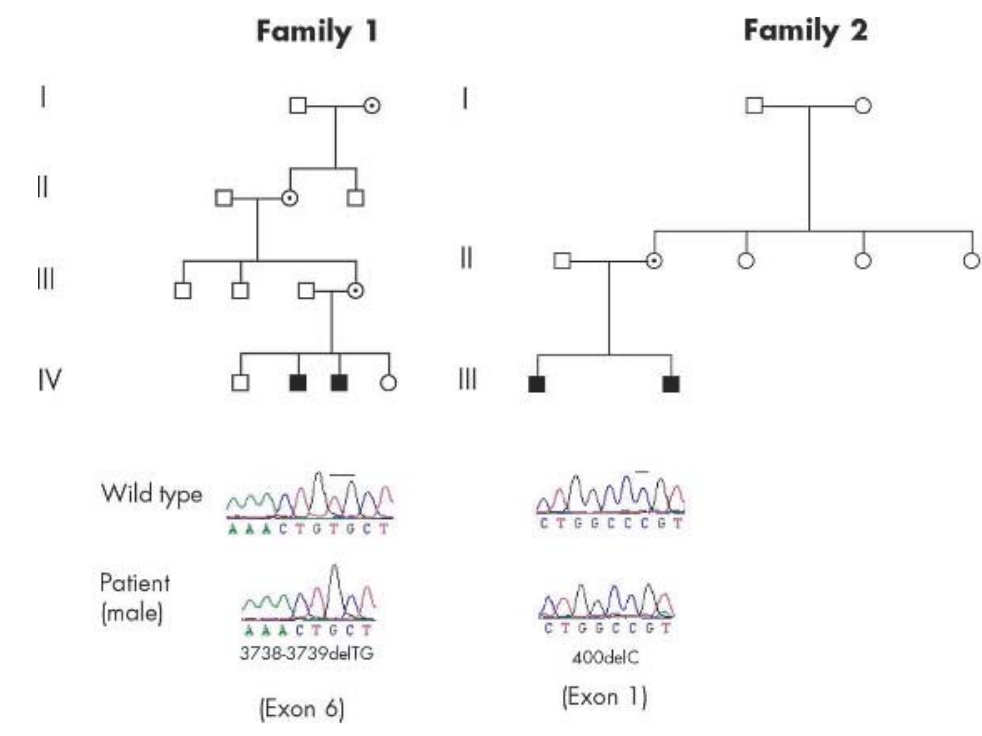

\section{Family 3}

Figure 1 Pedigrees of families with NHS and corresponding sequence chromatograms highlighting identified mutations. Squares denote males and circles, females. Filled squares represent affected individuals and circles with black dots represent females with features of NHS. 
A

NHS

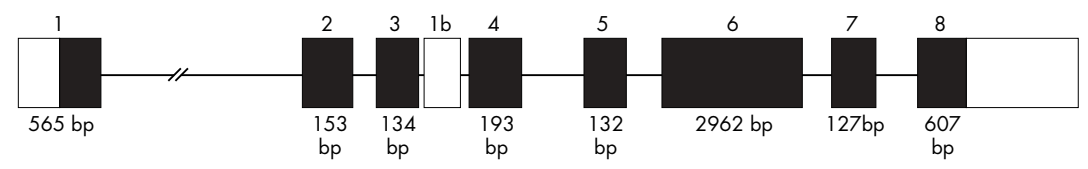

NHSL 1
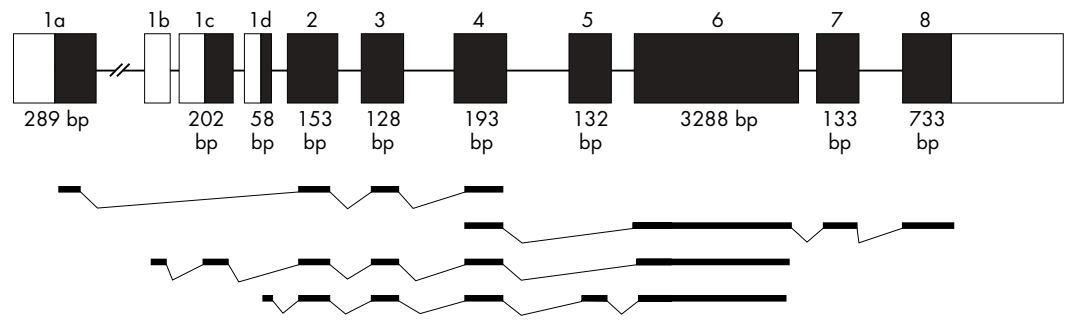

B
NHS (ExON 1) 1 MPFAKRIVEPQWLCRQRRP 19
NHSLI (EXOn 1) 1 MPFHQRTLEPARL---RRP 16
NHS (Exon 2) 189 PVSNLDIESKLSVYYRAPWHQQRNIFLPATRPPCVEELHRHA 230
$\begin{array}{lrl}\text { NHSLl (EXON 2) } & 97 \text { PVSNLDEESRWTVHYTAPWHQQENVFLPTTRPPCVEDLHRQA } & 138\end{array}$

NHS (Exon 4-5) 300 RPKNPIHNIPSTLDKQTNWSKALPLPTPEEKMKQDAQVISSCIIPINVTGVGFDREASIRCSL 362

NHSL 1 (EXON 4-5) 206 RPKTPASSDFSDLNTQTNWTKSLPLPTPEEKMRQQAQTVQADVVPINITGENFDRQASLRRSL 268

NHS (ExOn 5) $\quad 369$ LQRRRKL-RRRKTI 381

NHSLI (EXON 5) 274 LVRRPKKVKRRKTI 287

NHS (Exon 6) 421 SGTRDSECQTEDILIAAPSRRRIRAQRGQSIAA 453

NHSLI (Exon 6) $\quad 334$ SETRDSSCQTEDVKVVPPSMRRIRAQKGQGIAA 366

NHS (Exon 6) 969 QSESRATTPSLP--SVDNEFKLASPEKLAGLASPSSGYSSQSETPTSSFPTAFF 1020

NHSLl (ExOn 6) 894 QEGSRATMPQVPGGSVKP--KIMSPEKSHRVISPSSGYSSQSNTPTALTPVPVF 945

NHS (Exon 6) 1025 SP--GGSKRKPKVPERKSSL 1042

NHSLl (Exon 6) 950 SPANGKGKPKPKVPERKSSL 969

NHS (Exon 7-8) 1417 PRTTEDLFAVIHRSKRKVLGRKDSGD 1437

NHSL 1 (EXon 7-8) 1427 PRTTEDLFAAIHRSKRKVLGRKDSDD 1447

NHS (Exon 8) 1488 KSNTSNEEFKLLLLKKGSRSDSSYRMSATEILK 1520

NHSLl (Exon 8) 1488 KSSTSSSNFKALLLKKGSRSDTSARMSAAEMLK 1520

NHS (Exon 8) 1579 RVGRSRAPPAASSSRYSVRCRLYNTPMQAISEGETE 1614

NHSLl (EXOn 8) 1373 RYGRSRTPPSAASSRYSMRNRIQSSPMTVISEGEGE 1608

C

NHS

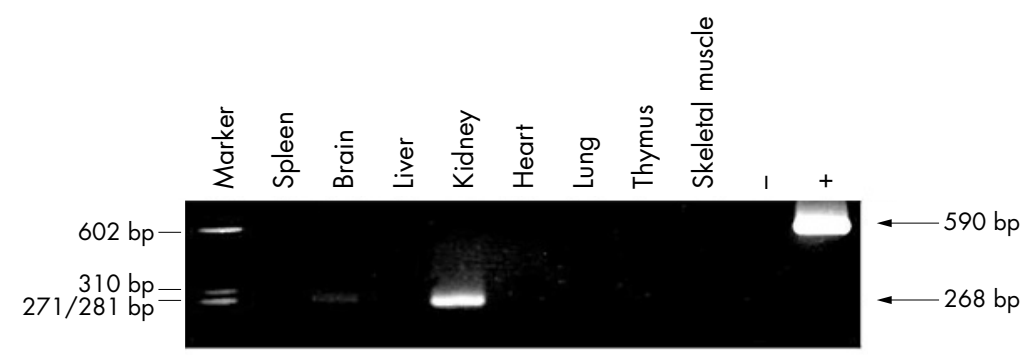

NHSL 1

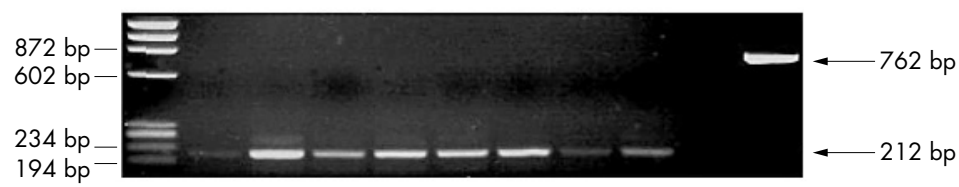

Figure 2 Comparison of NHS and NHSL1 genomic structures, protein sequences, and expression. (A) Genomic structure of the NHS gene alongside the predicted genomic structure for NHSL1 with supporting expression evidence. Blackened segments indicate the open reading frame (ORF) in each gene, with sizes of coding portions of exons below. Expressed sequence tags representing NHSL 1 show alternative $5^{\prime}$ ends and splicing out of exon 5 . (B) Partial protein alignment of human NHS and NHSL1, highlighting shared domains. Conserved amino acid residues are in bold. (C) Polymerase chain reaction from human fetal cDNA using primers designed to exon 6 and 7 of the NHS and NHSL1 genes; +, genomic DNA control; -, no DNA control. 
As the function of NHS is currently unknown we searched for homologies that may provide functional clues. We detected significant homology to sequence KIAA1357 located on chromosome 6q24.1 (www.ncbi.nlm.nih.gov/ using BLAST algorithms). This sequence was predicted to be a novel gene by computational analysis of supporting mRNA and EST evidence (including UniGene Cluster Hs.170162) from multiple tissues, including adult and fetal brain, fetal eyes, and adult lens, kidney, liver, and intestine. Inspection of the genomic interval (http://genome.ucsc.edu) revealed the structure of this novel gene, hereafter named NHSL1 (NHSLike1), on chromosome 6, with striking resemblance to the genomic structure of the NHS gene (fig $2 \mathrm{~A}$ ).

NHSL1 is predicted to be alternatively spliced with at least four alternative $5^{\prime}$ exons (la-ld) and a cryptic exon 5. Exon la lies $196 \mathrm{~kb}$ upstream of exon 2. Similarly, exon 1 of NHS is found $350 \mathrm{~kb}$ upstream of exon 2. In addition, exon la of NHSL1 has sequence homology at the protein level to NHS exon 1 (fig 2B). Exons 2, 4, and 5 of the NHS and NHSL1 genes are identical in size and show a high degree of protein homology (fig 2B). The terminal exons 6, 7, and 8 of both genes are very similar in size and also share protein homology; however, the large exon 6 of both genes is also divergent. Exon 3, again, is a similar size in both genes but encodes different protein sequences. The NHS and NHSL1 genes thus form a new gene family with strikingly similar genomic structure and a high degree of protein homology. We propose, therefore, that NHS and NHSL1 are isospecic heterofunctional paralogs. Furthermore, REPS1 and REPS2, lying telomeric to NHSL1 and NHS, respectively, are close paralogs which share $32 \%$ protein sequence identity. This implies that Xp22.13 and 6q24.1 are derived from a duplicated genomic sequence which has undergone significant sequence change throughout evolution but has retained sequence coding for conserved protein domains important to the function of these protein families.

To examine the expression of human NHSL1, primers to exon 6 and 7 were designed to amplify a $212 \mathrm{bp}$ fragment in cDNA or a 762 bp fragment in genomic DNA (Fw[5'AGCAGAGTGGAAGCCAATGTC-3'], Rev[5'- ACCTCATCATT CCCGTCTTCC-3']). NHSL1 transcripts were detected in all human fetal cDNA tissues tested (fig 2C). Interestingly, these corresponding exons in NHSL1 show a more ubiquitous expression than NHS.

\section{Conclusions}

In summary, we report the independent identification of the gene causative for Nance-Horan syndrome, and extend the number of mutations identified. No mutations were identified in the CXN family, raising the possibility that NHS and $\mathrm{CXN}$ are not allelic. Interestingly we have identified a second gene (NHSL1) with striking similarity to NHS, forming a new gene family lying in paralogous duplicated chromosomal intervals on Xp22 and 6q24. NHSL1 is more broadly expressed than NHS, as transcripts were detected in all fetal samples tested. We also detected additional expression of NHS in kidney, lung, and thymus, not reported in the original study.
Further functional characterisation of NHS is now essential to determine the pathological mechanism resulting in cataract-dental syndrome with variable additional symptoms including developmental delay.

\section{ACKNOWLEDGEMENTS}

We wish to thank the families for participating in this study and Dr Michel Michaelides for supplying the mouse tooth RNA. Thanks also to Dr Maryse Bailly and Dr Michael Cheetham for critical evaluation of this manuscript. This research was funded by Fight for Sight. SPB is a Fight for Sight prize PhD student.

\section{ELECTRONIC DATABASE INFORMATION}

Online Mendelian Inheritance in Man (OMIM): http://www.ncbi. nlm.nih.gov/Omim/ National Centre for Biotechnology Information home page: http://www.ncbi.nlm.nih.gov/

University of California, Santa Cruz home page: http://genome. ucsc.edu

ExPASy tools: http://ca.expasy.org/tools/

Gene and protein analysis using NIX and PIX: http://www.hgmp. mrc.ac.uk/

\section{Authors' affiliations}

S P Brooks, N D Ebenezer, S Poopalasundaram, A J Hardcastle, Division of Molecular Genetics, Institute of Ophthalmology, University College London, London $\mathrm{ECl}$, UK

O J Lehmann, A T Moore, Moorfields Eye Hospital, London ECl, UK

Conflicts of interest: none declared

\section{REFERENCES}

1 Horan MB, Billson FA. X-linked cataract and Hutchinsonian teeth. Aust Paediatr J 1974;10:98-102.

2 Nance WE, Warburg M, Bixler D, Helveston EM. Congenital X-linked cataract, dental anomalies and brachymetacarpalia. Birth Defects Orig Art Ser 1974;10:285-91.

3 van Dorp DB, Delleman JW. A family with X-chromosomal recessive congenital cataract, microphthalmia, a peculiar form of the ear and dental anomalies. J Pediatr Ophthalmol Strabismus 1979;16:166-71.

4 Bixler D, Higgins M, Hartsfield J. The Nance-Horan syndrome: a rare X-linked ocular-dental trait with expression in heterozygous females. Clin Genet 1984;26:30-5.

5 Seow WK, Brown JP, Romaniuk K. The Nance-Horan syndrome of dental anomalies, congenital cataracts, microphthalmia, and anteverted pinna: case report. Pediatr Dent 1985;7:307-11.

6 Francis PJ, Berry V, Hardcastle AJ, Maher ER, Moore AT, Bhattacharya SS. A locus for isolated cataract on human Xp. J Med Genet 2002;39:105-9.

7 Brooks SP, Ebenezer ND, Poopalasundaram S, Maher ER, Francis PJ, Moore AT, Hardcastle AJ. Refinement of the X-linked cataract locus (CXN) and gene analysis for CXN and Nance-Horan syndrome (NHS). Ophthalmic Genet (in press).

8 Burdon KP, McKay JD, Sale MM, Russell-Eggitt IM, Mackey DA, Wirth MG Elder JE, Nicoll A, Clarke MP, FitzGerald LM, Stankovich JM, Shaw MA Sharma S, Gajovic S, Gruss P, Ross S, Thomas P, Voss AK, Thomas T, Gecz J, Craig JE. Mutations in a novel gene, NHS, cause the pleiotropic effects of Nance-Horan syndrome, including severe congenital cataract, dental anomalies, and mental retardation. Am J Hum Genet 2003;73:1120-30.

9 Toutain A, Dessay B, Ronce N, Ferrante MI, Tranchemontagne J, NewburyEcob R, Wallgren-Pettersson C, Burn J, Kaplan J, Rossi A, Russo S, Walpole I, Hartsfield JK, Oyen N, Nemeth A, Bitoun P, Trump D, Moraine C, Franco B. Refinement of the NHS locus on chromosome Xp22.13 and analysis of five candidate genes. Eur J Hum Genet 2002;10:516-20.

10 Stambolian D, Favor J, Silvers W, Avner P, Chapman V, Zhou E. Mapping of the X-linked cataract (Xcat) mutation, the gene implicated in the Nance Horan syndrome, on the mouse X chromosome. Genomics 1994;22:377-80. 